\title{
Outcomes of Endoscopic Ultrasound-Guided Biliary Drainage in Patients Undergoing Antithrombotic Therapy
}

\author{
Nozomi Okuno', Kazuo Hara', Nobumasa Mizuno', Shin Haba', Takamichi Kuwahara', Hiroki Koda', Masahiro Tajika', Tsutomu \\ Tanaka ${ }^{2}$, Sachiyo Onishi' ${ }^{2}$ Keisaku Yamada ${ }^{2}$, Akira Miyano', Daiki Fumihara' and Moaz Elshair ${ }^{1}$ \\ Departments of ${ }^{1}$ Gastroenterology, ${ }^{2}$ Endoscopy, Aichi Cancer Center Hospital, Nagoya, Japan
}

Background/Aims: The Japan Gastroenterological Endoscopy Society (JGES) has published guidelines for gastroenterological endoscopy in patients undergoing antithrombotic treatment. These guidelines classify endoscopic ultrasound-guided biliary drainage (EUS-BD) as a high-risk procedure. Nevertheless, the bleeding risk of EUS-BD in patients undergoing antithrombotic therapy is uncertain. Therefore, this study aimed to assess the bleeding risk in patients undergoing antithrombotic therapy.

Methods: This single-center retrospective study included 220 consecutive patients who underwent EUS-BD between January 2013 and December 2018. We managed the withdrawal and continuation of antithrombotic agents according to the JGES guidelines. We compared the bleeding event rates among patients who received and those who did not receive antithrombotic agents.

Results: A total of 18 patients (8.1\%) received antithrombotic agents and 202 patients $(91.8 \%)$ did not. Three patients experienced bleeding events, with an overall bleeding event rate of $1.3 \%(3 / 220)$ : one patient was in the antithrombotic group (5.5\%) and two patients were in the non-antithrombotic group $(0.9 \%)(p=0.10)$. All cases were moderate. The sole thromboembolic event $(0.4 \%)$ was a cerebral infarction in a patient in the non-antithrombotic group.

Conclusions: The rate of EUS-BD-related bleeding events was low. Even in patients receiving antithrombotic therapy, the bleeding event rates were not significantly different from those in patients not receiving antithrombotic therapy. Clin Endosc 2021;54:596-602

Key Words: Anticoagulant agents; Antiplatelet agents; Antithrombotic agents; Bleeding; EUS-guided biliary drainage

\section{INTRODUCTION}

Antithrombotic agents (ATAs), including antiplatelet agents, anticoagulants, and direct oral anticoagulants (DOACs), are widely prescribed for cerebrovascular disorders, cardiovascular disorders, and thromboembolisms. However, they increase the risk of bleeding during therapeutic endoscopic procedures, whereas their discontinuation increases the risk of thrombo-

Received: July 18, 2020 Revised: September 10,2020

Accepted: November 3, 2020

Correspondence: Kazuo Hara

Department of Gastroenterology, Aichi Cancer Center Hospital, 1-1 Kanokoden, Chikusa-ku, Nagoya, Aichi 464-8681, Japan

Tel: +81-52-762-6111, Fax: +81-52-763-5233, E-mail: khara@aichi-cc.jp

ORCID: https://orcid.org/0000-0002-4699-6136

(cc) This is an Open Access article distributed under the terms of the Creative Commons Attribution Non-Commercial License (http://creativecommons.org/ licenses/by-nc/3.0) which permits unrestricted non-commercial use, distribution, and reproduction in any medium, provided the original work is properly cited. embolism. Several guidelines for antithrombotic management in endoscopy have been published. ${ }^{1-3}$ The Japan Gastroenterological Endoscopy Society (JGES) has also published guidelines for gastroenterological endoscopy in patients undergoing antithrombotic treatment in 2012. ${ }^{4}$ These guidelines classify endoscopic ultrasound-guided fine-needle aspiration (EUSFNA) and endoscopic ultrasound-guided biliary drainage (EUS-BD) as high-risk procedures, and recommend periprocedural mangement based on the type of antithrombotic agents and patient risk. However, there are few reports about bleeding related to EUS-FNA in patients undergoing antithrombotic therapy. ${ }^{5-8}$ Moreover, there is almost no available evidence on EUS-BD in patients undergoing antithrombotic therapy. As EUS-BD requires dilation and stent placement as well as puncture, it may influence the incidence of bleeding events. Therefore, the aim of this study was to determine the outcomes of EUS-BD, particularly bleeding and thromboembolism, in patients undergoing antithrombotic therapy. 


\section{MATERIALS AND METHODS}

\section{Patients}

We applied treatment with ATAs according to the 2012 JGES guidelines. A total of 220 consecutive patients underwent EUS-BD (EUS-guided hepaticoenterostomy [EUS-HES] or EUS-guided choledocoduodenostomy [EUS-CDS]) between January 2013 and December 2018 at Aichi Cancer Center. We categorized patients who received ATAs into the ATA group and those who did not into the non-ATA group. All patients provided informed consent for the procedures, and the local institutional review board approved the study (approval no. 2019-1-254). Patients were prospectively enrolled, and clinical data were retrospectively collected for these 220 cases.

The JGES guidelines classify EUS-BD as a high-risk procedure for bleeding. ATAs were categorized into five subgroups based on the guidelines, as follows: (1) aspirin, (2) thienopyridine derivatives, (3) antiplatelet agents other than thienopyridine, (4) warfarin, and (5) DOACs. When ATAs needed to be withdrawn before EUS-BD, we consulted the primary doctor. We managed the withdrawal and continuation of ATAs based on the 2012 JGES guidelines (Table 1). The same regimen was resumed as soon as hemostasis was confirmed.

\section{Endoscopic ultrasound-guided biliary drainage}

EUS-BD was performed by skilled endosonographers. Antibiotics were permitted in all cases before and after the intervention. During this study period, we performed EUS$\mathrm{BD}$ not only as a rescue procedure after a failed endoscopic retrograde cholangiopancreatography (ERCP), but also for primary drainage. We performed EUS-HES as the primary drainage procedure for cases in which ERCP was difficult (e.g., in patients with duodenal obstruction or a surgically altered anatomy), whereas we performed EUS-CDS as the primary drainage procedure for cases of unresectable malignant lower biliary obstruction.

\section{Endoscopic ultrasound-guided hepaticoenterostomy}

EUS-HES was performed using a convex echo-endoscope (GU-UCT260 [Olympus Medical Systems, Tokyo, Japan] or EG-580UT [Fujifilm, Tokyo, Japan]). First, we used a forward-viewing scope to clip the gastroesophageal junction for easy identification and prevention of esophageal puncture. We have experienced severe adverse events, such as mediastinal emphysema and pneumothorax, when performing transesophageal EUS-guided rendezvous. ${ }^{9}$ We were able to easily confirm the position of the clip under fluoroscopy. We attached a connector (Radifocus Hemostasis Valve II; Terumo, Tokyo, Japan) to a needle in advance. Puncture of the intrahepatic bile duct was performed using a 19-gauge needle guided by color Doppler imaging to avoid vessels. Once the bile duct was punctured, we inserted a 0.025 -in. guidewire, which was used to stabilize the needle. Subsequently, we injected a small amount of contrast medium. Thereafter, a guidewire was placed into the common bile duct and we gradually dilated the fistula using a dilator catheter (ES dilator soft type; Zeon Medical, Tokyo, Japan) and/or an uneven double-lumen cannula (Piolax Medical, Yokohama, Japan) and/or a balloon catheter (REN 4 mm; Kaneka Medical Products, Tokyo, Japan). Finally, we placed a stent. We mainly used a fully covered self-expandable metal stent (FCSEMS; $6 \mathrm{~mm} \times 10 \mathrm{~cm}$ or $12 \mathrm{~cm}$, HANAROSTENT; Boston Scientific, Tokyo, Japan).

\section{Endoscopic ultrasound-guided choledocoduodenostomy}

EUS-CDS was performed using a forward-viewing convex echo-endoscope (TGF-UC260J; Olympus Medical Systems) or an oblique-viewing convex echo-endoscope (GU-UCT260 [Olympus Medical Systems] or EG-580UT [Fujifilm]) to identify the extrahepatic bile duct from the duodenal bulb. The extrahepatic bile duct was punctured using a 19-gauge needle to evaluate the biliary tree. Thereafter, we inserted a 0.025 -in. guidewire and dilated the fistula using a 6-Fr diathermic dilator (Cysto-Gastro-Set; Endo-Flex, Voerde, Germany) over the

Table 1. Withdrawal and Continuation Method of Antithrombotic Agents in Endoscopic Ultrasound-Guided Biliary Drainage

\begin{tabular}{ll}
\hline Aspirin & \multicolumn{1}{c}{ Continuation } \\
\hline Thienopyridine derivatives & Withdraw for 5 days and replaced with aspirin \\
Antiplatelet agents other than thienopyridine & Withdraw for 1 day \\
Warfarin & PT-INR greater than the therapeutic range \\
& Withdraw for 3 days with replacement by intravenous heparin $(10,000-20,000$ units/day) \\
& Stop intravenous heparin 4-6 hr before EUS-BD
\end{tabular}

DOACs, direct oral anticoagulants; EUS-BD, endoscopic ultrasound-guided biliary drainage; PT-INR, prothrombin time-international normalized ratio. 
guidewire with a pure-cut setting. Finally, we placed a stent. We mainly used an FCSEMS $(10 \mathrm{~mm} \times 6 \mathrm{~cm}$ X-SuitNIR; Olympus Medical Systems).

\section{Outcome measurements}

We evaluated the outcomes in terms of bleeding and thromboembolic events, especially stroke and pulmonary embolism. Bleeding events were defined according to the definitions of the American Society for Gastrointestinal Endoscopy. ${ }^{10}$

Bleeding events were defined as hematemesis, melena, or a $>2 \mathrm{~g} / \mathrm{dL}$ decrease in hemoglobin levels compared with baseline, without any clinical conditions contradicting the finding of bleeding. Severity grading was defined according to the definitions of the American Society for Gastrointestinal Endoscopy. ${ }^{10}$ Blood tests were performed before and after EUS$\mathrm{BD}$, and plain computed tomography (CT) was performed after EUS-BD. Contrast CT was performed as required in patients suspected of having experienced adverse events, such as bleeding, based on symptoms or laboratory tests.

\section{Statistical analysis}

The primary outcomes were the EUS-BD-related bleeding and thromboembolic event rates. The secondary outcomes were the risk factors for bleeding in EUS-BD.

Categorical parameters were compared using the chi-square or Fisher's exact test, and hazard ratios were calculated using the Cox proportional-hazard model. Two-sided $p$-values $<0.05$ were considered significant. All data were analyzed using StatMate V statistical software (ATMS, Tokyo, Japan).

\section{RESULTS}

During the study period, 220 patients underwent EUS-BD. Of these, 18 patients had been receiving and 202 patients had not been receiving antithrombotic therapy. The patients' characteristics are shown in Table 2. The median age of the patients in the ATA group was 73.5 years (range, $56-88$ years), and $66.6 \%$ were men (12 men, 6 women). No significant differenc-

Table 2. Patient Characteristics

\begin{tabular}{|c|c|c|c|}
\hline & ATA group $(n=18)$ & Non-ATA group $(n=202)$ & $p$-value \\
\hline Age, median (range) & $73.5(56-88)$ & $68(37-94)$ & 0.40 \\
\hline Sex, male/female & $12 / 6$ & $119 / 83$ & 0.52 \\
\hline $\begin{array}{l}\text { Disease } \\
\text { Malignant biliary obstruction } \\
\text { Benign biliary stricture }\end{array}$ & $\begin{array}{c}16 \\
2\end{array}$ & $\begin{array}{c}189 \\
13\end{array}$ & 0.79 \\
\hline $\begin{array}{l}\text { Number of comorbidities }(n) \\
>3 \\
3 \\
2 \\
1 \\
0\end{array}$ & $\begin{array}{l}0 \\
4 \\
7 \\
7 \\
0\end{array}$ & $\begin{array}{c}1 \\
6 \\
22 \\
57 \\
116\end{array}$ & $<0.001$ \\
\hline $\begin{array}{l}\text { Comorbidities }(n)^{\mathrm{a})} \\
\text { Hypertension } \\
\text { Diabetes mellitus } \\
\text { Hyperlipidemia } \\
\text { Coronary artery disease } \\
\text { Cerebral infraction } \\
\text { Atrial fibrillation } \\
\text { Deep vein thrombosis } \\
\text { Valvular heart disease } \\
\text { Liver cirrhosis } \\
\text { Congestive heart failure } \\
\text { Others }\end{array}$ & $\begin{array}{l}9 \\
3 \\
4 \\
1 \\
8 \\
4 \\
2 \\
0 \\
0 \\
0 \\
3\end{array}$ & $\begin{array}{c}48 \\
33 \\
19 \\
0 \\
0 \\
0 \\
1 \\
1 \\
2 \\
1 \\
9\end{array}$ & \\
\hline Hemoglobin (g/dL, mean \pm SD) & $11.1 \pm 2.13$ & $10.8 \pm 1.92$ & 0.32 \\
\hline Platelet $\left(\times 10^{4} / \mu \mathrm{L}\right.$, mean $\left.\pm \mathrm{SD}\right)$ & $24.6 \pm 7.84$ & $25.1 \pm 12.45$ & 0.40 \\
\hline PT-INR $($ mean \pm SD $)$ & $1.45 \pm 0.85$ & $1.15 \pm 0.33$ & $0.02^{\mathrm{b})}$ \\
\hline
\end{tabular}

ATA, antithrombotic agent; PT-INR, prothrombin time-international normalized ratio; SD, standard deviation.

${ }^{\text {a) }}$ Some overlap was noted.

${ }^{\mathrm{b}}$ Statistically significant $(p<0.05)$. 
es were observed between the ATA and non-ATA groups. In both groups, most patients had malignant biliary obstruction. The ATA group had significantly more comorbidities than the non-ATA group $(p<0.001)$. The baseline hemoglobin levels and platelet counts were not significantly different between the two groups. The prothrombin time-international normalized ratio (PT-INR) was significantly higher in the ATA group than in the non-ATA group $(p<0.05)$.

Of the 18 patients $(8.1 \%)$ receiving antithrombotic therapy, 13 patients received antiplatelet therapy (aspirin $[n=5]$, thienopyridine [ $n=3]$, antiplatelet agent other than thienopyridine $[n=4]$, and aspirin and thienopyridine $[n=1])$ and 5 patients received anticoagulant therapy (DOACs) (Table 3). EUS-BD was performed with continuation of aspirin in 7 patients, discontinuation of agents in 10 patients, and heparin replacement in 1 patient (Fig. 1).

The observed adverse events are shown in Table 4 . The overall adverse event rate was $16.3 \%(36 / 220)$. The adverse event rate was $11.1 \%(2 / 18)$ in the ATA group and $16.8 \%(34 / 202)$ in the non-ATA group, with no significant difference between

Table 3. Types of Drugs Used in 18 Patients Undergoing Antithrombotic Therapy

\begin{tabular}{ll}
\hline & $\mathbf{n = 1 8}$ \\
\hline Antiplatelet agents & 5 \\
Aspirin & 3 \\
Thienopyridine & 4 \\
Antiplatelet agent other than thienopyridine & 1 \\
Aspirin + thienopyridine & \\
Anticoagulant agents & 0 \\
Warfarin & 5 \\
Direct oral anticoagulant & \\
\hline
\end{tabular}

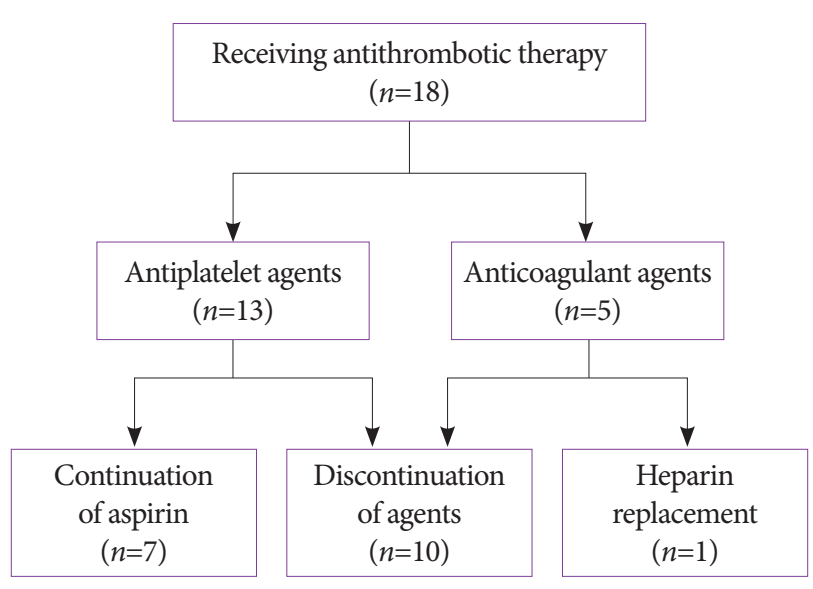

Fig. 1. Flowchart of 18 patients who received antithrombotic therapy.
Table 4. Adverse Events

\begin{tabular}{lccc}
\hline & $\begin{array}{c}\text { ATA group } \\
(\boldsymbol{n}=\mathbf{1 8})\end{array}$ & $\begin{array}{c}\text { Non ATA } \\
\text { group } \\
(\boldsymbol{n}=\mathbf{2 0 2})\end{array}$ & $\boldsymbol{p}$-value \\
\hline Overall & 2 & 34 & 0.76 \\
Bleeding & 1 & 2 & 0.10 \\
Peritonitis & 0 & 10 & \\
Fever & 0 & 7 & \\
Cholangitis & 0 & 6 & \\
Cholecystitis & 1 & 3 & \\
Biloma & 0 & 1 & \\
Pneumonia & 0 & 1 & \\
Others & 0 & 4 & \\
Hemoglobin decrease & $0.77 \pm 0.48$ & $0.75 \pm 0.57$ & 0.43 \\
(g/dL, mean \pm SD $)$ & & & \\
Blood transfusion & 1 & 2 & 0.21 \\
Thromboembolic events & 0 & 1 & 0.76 \\
Cerebral infraction & 0 & 1 & \\
Deep vein thrombosis & 0 & 0 & \\
\hline
\end{tabular}

ATA, antithrombotic agent; SD, standard deviation.

the two groups $(p=0.76)$. Bleeding occurred in three patients (1.3\%): one patient (5.5\%) in the ATA group and two patients $(0.9 \%)$ in the non-ATA group. No significant difference was observed between the groups $(p=0.10)$. A thromboembolic event occurred in only one patient $(0.4 \%[1 / 220])$ in the nonATA group. This patient developed acute cerebral infarction on the day after EUS-HES. The patient had pancreatic ductal cancer with liver metastasis recurrence but no other comorbidities.

The details of patients with bleeding events are shown in Table 5. Relevant bleeding events occurred in three patients. All of these patients required transfusion and various approaches such as repeat endoscopy or interventional radiology. No deaths occurred in all patients.

The factors associated with bleeding are provided in Table 6 . The median procedure time was $25 \mathrm{~min}$ (range, 5-176 $\mathrm{min}$ ). In the univariate analysis, the rate of bleeding did not significantly differ according to antithrombotic therapy $(p=0.10)$, age $(p=0.55)$, platelet count $(p=0.66)$, PT-INR $(p=0.77)$, primary disease $(p=0.06)$, approach route $(p=0.46)$, ascites $(p=0.64)$, stent type $(p=0.38)$, or procedure time $(p=0.74)$. Only the use of an electrical device to perform dilation was significantly higher in patients who experienced bleeding $(p<0.05)$. 
Table 5. Details of Cases with Bleeding Events

\begin{tabular}{|c|c|c|c|c|c|c|c|c|c|c|c|c|c|}
\hline Case & $\begin{array}{l}\text { Age/ } \\
\text { sex }\end{array}$ & $\begin{array}{l}\text { Primary } \\
\text { disease }\end{array}$ & $\begin{array}{l}\text { EUS- } \\
\text { BD }\end{array}$ & $\begin{array}{c}\text { Dila- } \\
\text { tion } \\
\text { device }\end{array}$ & Stent & ATD & $\begin{array}{c}\begin{array}{c}\text { Man- } \\
\text { age- } \\
\text { ment of } \\
\text { ATD }\end{array}\end{array}$ & $\begin{array}{c}\text { Tim- } \\
\text { ing }\end{array}$ & $\begin{array}{l}\text { Symp- } \\
\text { tom }\end{array}$ & $\begin{array}{l}\text { Grad- } \\
\text { ing }\end{array}$ & $\begin{array}{l}\text { Type of bleed- } \\
\text { ing }\end{array}$ & $\begin{array}{c}\text { Hemostasis } \\
\text { treatment }\end{array}$ & $\begin{array}{c}\text { Transfu- } \\
\text { sion }\end{array}$ \\
\hline 1 & $64 / \mathrm{M}$ & $\begin{array}{l}\text { Pancreat- } \\
\text { ic cancer }\end{array}$ & CDS & $\begin{array}{l}\text { Electri- } \\
\text { cal }\end{array}$ & Metal & $\begin{array}{l}\text { Clopi- } \\
\text { dogrel }\end{array}$ & $\begin{array}{l}\text { Contin- } \\
\text { uation } \\
\text { of } \\
\text { aspirin }\end{array}$ & Post & Melena & $\begin{array}{l}\text { Mod- } \\
\text { erate }\end{array}$ & $\begin{array}{l}\text { Endoscopic ex- } \\
\text { amination with } \\
\text { no evidence of } \\
\text { active bleeding }\end{array}$ & $\begin{array}{c}\text { Conservative } \\
\text { treatment }\end{array}$ & + \\
\hline 2 & $57 / \mathrm{F}$ & $\begin{array}{l}\text { Lung } \\
\text { cancer }\end{array}$ & CDS & $\begin{array}{l}\text { Electri- } \\
\text { cal }\end{array}$ & Metal & - & - & Intra & $\begin{array}{l}\text { Hemo- } \\
\text { bilia }\end{array}$ & $\begin{array}{l}\text { Mod- } \\
\text { erate }\end{array}$ & Hemobilia & $\begin{array}{l}\text { Interventional } \\
\text { radiology }\end{array}$ & + \\
\hline 3 & $64 / \mathrm{F}$ & $\begin{array}{l}\text { Anas- } \\
\text { tomosis } \\
\text { stricture }\end{array}$ & HES & $\begin{array}{l}\text { Electri- } \\
\text { cal }\end{array}$ & Metal & - & - & Post & Melena & $\begin{array}{l}\text { Mod- } \\
\text { erate }\end{array}$ & Aneurysm & $\begin{array}{l}\text { Interventional } \\
\text { radiology }\end{array}$ & + \\
\hline
\end{tabular}

ATD, antithrombotic drug; CDS, choledocoduodenostomy; EUS-BD, endoscopic ultrasound-guided biliary drainage; HES, hepaticoenterostomy.

Table 6. Analysis of Factors Associated with Bleeding

\begin{tabular}{|c|c|c|c|c|}
\hline \multirow{2}{*}{ Factors } & \multirow{2}{*}{$\begin{array}{l}\text { Bleeding group } \\
\qquad(n=3)\end{array}$} & \multirow{2}{*}{$\begin{array}{l}\text { Non-bleeding group } \\
\qquad(n=217)\end{array}$} & \multicolumn{2}{|c|}{ Univariate } \\
\hline & & & OR & $p$-value \\
\hline Antithrombotic therapy & $\begin{array}{c}33.3 \% \\
(1 / 3)\end{array}$ & $\begin{array}{c}78.3 \% \\
(17 / 217)\end{array}$ & 5.88 & 0.10 \\
\hline Age $(\geq 80 \mathrm{yr})$ & $\begin{array}{c}0 \% \\
(0 / 3)\end{array}$ & $\begin{array}{c}10.5 \% \\
(23 / 217)\end{array}$ & 0 & 0.55 \\
\hline Platelet $\left(<10 \times 10^{4} / \mu \mathrm{L}\right)$ & $\begin{array}{c}0 \% \\
(0 / 3)\end{array}$ & $\begin{array}{c}5.9 \% \\
(13 / 217)\end{array}$ & 0 & 0.66 \\
\hline PT-INR ( $\geq 1.5)$ & $\begin{array}{c}0 \% \\
(0 / 3)\end{array}$ & $\begin{array}{c}2.7 \% \\
(6 / 217)\end{array}$ & 0 & 0.77 \\
\hline Primary disease (malignancy) & $\begin{array}{c}66.6 \% \\
(2 / 3)\end{array}$ & $\begin{array}{c}93.5 \% \\
(203 / 217)\end{array}$ & 0.13 & 0.06 \\
\hline Approach route (transhepatic) & $\begin{array}{c}33.3 \% \\
(1 / 3)\end{array}$ & $\begin{array}{c}54.3 \% \\
(118 / 217)\end{array}$ & 0.41 & 0.46 \\
\hline Ascites (present) & $\begin{array}{c}33.3 \% \\
(1 / 3)\end{array}$ & $\begin{array}{c}46.5 \% \\
(101 / 217)\end{array}$ & 0.57 & 0.64 \\
\hline Stent (FCSEMS) & $\begin{array}{c}100.0 \% \\
(3 / 3)\end{array}$ & $\begin{array}{c}79.7 \% \\
(173 / 217)\end{array}$ & - & 0.38 \\
\hline Procedure time (>25 min) & $\begin{array}{c}33.3 \% \\
(1 / 3)\end{array}$ & $\begin{array}{c}42.8 \% \\
(93 / 217)\end{array}$ & 0.66 & 0.74 \\
\hline Dilation device (electrical) & $\begin{array}{c}100.0 \% \\
(3 / 3)\end{array}$ & $\begin{array}{c}37.3 \% \\
(81 / 217)\end{array}$ & - & $0.02^{\mathrm{a})}$ \\
\hline
\end{tabular}

FCSEMS, fully covered self-expandable metal stent; OR, odds ratio; PT-INR, prothrombin time-international normalized ratio.

${ }^{\text {a) }}$ Statistically significant $(p<0.05)$.

\section{DISCUSSION}

The JGES guidelines also classify EUS-FNA as a high-risk procedure for bleeding. ${ }^{4}$ Two previous studies from Japan on
EUS-FNA in patients with antithrombotic therapy found a low incidence of EUS-FNA-related bleeding in patients receiving antithrombotic therapy $(0.4 \%-1.0 \%) .{ }^{6.8}$ The bleeding event rate was low even in patients who underwent EUS-FNA while 
continuing antithrombotic therapy.

The bleeding risk was found to increase according to the type of antithrombotic drugs (e.g., warfarin and heparin). Bridging warfarin with heparin increased the overall risk of major bleeding without a significant decrease in the risk of thromboembolic events. ${ }^{11,12}$

Continuation of oral anticoagulation therapy with an INR level of $<2.5$ does not impose an increased risk of bleeding for device-related procedures. ${ }^{13}$ The Japanese guidelines released a supplement about anticoagulants in 2017. ${ }^{14}$ The guidelines recommend continuation of warfarin or discontinuation of DOAC only on the morning of the procedure.

A prospective multicenter study evaluating the bleeding risk after EUS-FNA found that there were no bleeding events in any of the patients who took aspirin or cilostazol without discontinuation. ${ }^{7}$ This finding was consistent with those of other single-center studies. ${ }^{6.8}$ In the present study, the number of patients in the ATA group (especially in the anticoagulant group) was small. Therefore, we could not make a judgment about the differences among the antithrombotic drugs.

The JGES guidelines also classify endoscopic sphincterotomy (EST) as a high-risk procedure for bleeding. A previous study that investigated the risk factors for delayed hemorrhage after EST reported an overall bleeding rate of $2.7 \%$. The risk factors identified were hemodialysis $(p=0.0013)$, heparin replacement $(p=0.012)$, and early hemorrhage $(p<0.001) .{ }^{15} \mathrm{An}$ other study of bleeding after EST and papillary balloon dilation among users of ATAs found that the overall rate of severe bleeding was $0.8 \%$. The use of anticoagulants was associated with a statistically significant increase in severe bleeding. ${ }^{16}$

In a pooled analysis, the Japanese clinical practice guidelines suggested that the rate of bleeding in EUS-CDS was 2.5\% and the rate of bleeding in EUS-HGS was 3.7\%. No mortality related to bleeding was reported. ${ }^{17}$ In the present study, we experienced only three cases of bleeding. The rate of EUS-BD-related bleeding events was only $1.3 \%$. Even in patients receiving antithrombotic therapy, the bleeding event rate was not significantly different. All cases were moderate, and there were no fatal cases.

The Japanese clinical practice guidelines on EUS- $\mathrm{BD}^{17}$ recommend that, to avoid bleeding during EUS-BD, blood vessels along the puncture route should be evaluated using contrast CT or color Doppler EUS. The use of a needle knife that is not coaxial to the indwelling guidewire should be avoided. To prevent bleeding from fistulas, the use of a covered SEMS is recommended. In the present study, we used a coaxial device. The only factor associated with bleeding was the use of an electrical dilation device. Other factors such as antithrombotic therapy, age, platelet count, and PT-INR were not significantly associated with bleeding. EUS-BD is used not only as an alternative method after a failed ERCP but also for primary drainage. 18,19 EUS-BD may be safely performed in high-risk patients such as elderly patients or those with low platelet counts. Similar to EST, EUS-BD can also be performed in patients undergoing antithrombotic treatment managed according to the JGES guidelines.

The major limitation of this study was the small number of patients in the ATA group, especially in the anticoagulant group. Moreover, this was a retrospective and single-center study. To confirm the findings of the present study, a larger prospective multicenter study of patients with high-risk factors, such as use of anticoagulants, is needed in the future.

In conclusion, the rate of EUS-BD-related bleeding events was low. Even in patients who received antithrombotic therapy managed according to the JGES guidelines, the bleeding event rates were not significantly different from those who did not receive antithrombotic therapy. Before EUS-BD, the risks of both thromboembolic events and bleeding should be considered. The use of an electrical dilation device was a risk factor associated with bleeding in this study. Therefore, a patient's bleeding risk should be considered before using an electrical dilation device, and if it is used, close monitoring of the patient is essential.

\section{Conflicts of Interest}

The authors have no potential conflicts of interest.

Funding

None.

ORCID
Nozomi Okuno:

Kazuo Hara:

Nobumasa Mizuno:

Shin Haba:

Takamichi Kuwahara:

Hiroki Koda:

Masahiro Tajika:

Tsutomu Tanaka:

Sachiyo Onishi:

Keisaku Yamada:

Akira Miyano:

Daiki Fumihara:

Moaz Elshair:
https://orcid.org/0000-0001-6376-687X https://orcid.org/0000-0002-4699-6136 https://orcid.org/0000-0001-9704-1885 https://orcid.org/0000-0002-7578-5610 https://orcid.org/0000-0001-8348-8926 https://orcid.org/0000-0003-4000-6899 https://orcid.org/0000-0002-3761-6971 https://orcid.org/0000-0002-7397-7360 https://orcid.org/0000-0001-8633-1019 https://orcid.org/0000-0002-6101-4524 https://orcid.org/0000-0001-7313-0349 https://orcid.org/0000-0002-5424-492X https://orcid.org/0000-0003-2921-7417

\section{REFERENCES}

1. Veitch AM, Baglin TP, Gershlick AH, Harnden SM, Tighe R, Cairns S. Guidelines for the management of anticoagulant and antiplatelet therapy in patients undergoing endoscopic procedures. Gut 2008;57:1322-1329.

2. ASGE Standards of Practice Committee; Anderson MA, Ben-Menachem T, et al. Management of antithrombotic agents for endoscopic procedures. Gastrointest Endosc 2009;70:1060-1070. 
3. Boustière C, Veitch A, Vanbiervliet G, et al. Endoscopy and antiplatelet agents. European Society of Gastrointestinal Endoscopy (ESGE) guideline. Endoscopy 2011;43:445-461.

4. Fujimoto K, Fujishiro M, Kato M, et al. Guidelines for gastroenterological endoscopy in patients undergoing antithrombotic treatment. Dig Endosc 2014;26:1-14.

5. Kien-Fong Vu C, Chang F, Doig L, Meenan J. A prospective control study of the safety and cellular yield of EUS-guided FNA or Trucut biopsy in patients taking aspirin, nonsteroidal anti-inflammatory drugs, or prophylactic low molecular weight heparin. Gastrointest Endosc 2006;63:808-813.

6. Inoue T, Okumura F, Sano H, et al. Bleeding risk of endoscopic ultrasound-guided fine-needle aspiration in patients undergoing antithrombotic therapy. Dig Endosc 2017;29:91-96.

7. Kawakubo K, Yane K, Eto K, et al. A prospective multicenter study evaluating bleeding risk after endoscopic ultrasound-guided fine needle aspiration in patients prescribed antithrombotic agents. Gut Liver 2018;12:353-359.

8. Polmanee P, Hara K, Mizuno N, et al. Outcomes of EUS-FNA in patients receiving antithrombotic therapy. Endosc Int Open 2019;7:E15-E25.

9. Okuno N, Hara K, Mizuno N, et al. Risks of transesophageal endoscopic ultrasonography-guided biliary drainage. International Journal of Gastrointestinal Intervention 2017;6:82-84

10. Cotton PB, Eisen GM, Aabakken L, et al. A lexicon for endoscopic adverse events: report of an ASGE workshop. Gastrointest Endosc 2010;71:446-454.

11. Baron TH, Kamath PS, McBane RD. Antithrombotic therapy and invasive procedures. N Engl J Med 2013;369:1079-1080.
12. Douketis JD, Spyropoulos AC, Kaatz S, et al. Perioperative bridging anticoagulation in patients with atrial fibrillation. N Engl J Med 2015;373:823-833.

13. Li HK, Chen FC, Rea RF, et al. No increased bleeding events with continuation of oral anticoagulation therapy for patients undergoing cardiac device procedure. Pacing Clin Electrophysiol 2011;34:868-874.

14. Kato M, Uedo N, Hokimoto S, et al. Guidelines for gastroenterological endoscopy in patients undergoing antithrombotic treatment: 2017 appendix on anticoagulants including direct oral anticoagulants. Dig Endosc 2018;30:433-440.

15. Ikarashi S, Katanuma A, Kin T, et al. Factors associated with delayed hemorrhage after endoscopic sphincterotomy: Japanese large single-center experience. J Gastroenterol 2017;52:1258-1265.

16. Hamada T, Yasunaga H, Nakai Y, et al. Bleeding after endoscopic sphincterotomy or papillary balloon dilation among users of antithrombotic agents. Endoscopy 2015;47:997-1004.

17. Isayama $\mathrm{H}$, Nakai $\mathrm{Y}$, Itoi $\mathrm{T}$, et al. Clinical practice guidelines for safe performance of endoscopic ultrasound/ultrasonography-guided biliary drainage: 2018. J Hepatobiliary Pancreat Sci 2019;26:249-269.

18. Okuno N, Hara K, Mizuno N, et al. Efficacy of the 6-mm fully covered self-expandable metal stent during endoscopic ultrasound-guided hepaticogastrostomy as a primary biliary drainage for the cases estimated difficult endoscopic retrograde cholangiopancreatography: a prospective clinical study. J Gastroenterol Hepatol 2018;33:1413-1421.

19. Matsumoto S, Hara K, Mizuno N, et al. Risk factor analysis for adverse events and stent dysfunction of endoscopic ultrasound-guided choledochoduodenostomy. Dig Endosc 2020;32:957-966. 